\title{
Allergy Practices in Otorhinolaryngology Residency Programs in Turkey: Quo Vadis?
}

\section{Original Investigation $>$ Erdem Mengi, $\bullet$ Cüneyt Orhan Kara, $\bullet$ Bülent Topuz}

Department of Otolarhinolaryngology, Head and Neck Surgery, Pamukkale University School of Medicine, Denizli, Turkey

This study was presented in part at the Turkish Otorhinolaryngology and Head and Neck Surgery Virtual Congress 2020; November $26^{\text {th }}-28^{\text {th }}, 2020$.

\section{ORCID ID of the authors:}

E.M. 0000-0001-8813-2443; C.O.K. 00000-0003-2219-4283 B.T. 0000-0001-7895-6190

Cite this article as: Mengi E, Kara CO, Topuz B. Allergy Practices in Otorhinolaryngology Residency Programs in Turkey: Quo Vadis?

TurkArchOtorhinolaryngol2021;59(2):118-23.

Corresponding Author:

Erdem Mengi; emengi@hotmail.com

Received Date: 30.11 .2020

Accepted Date: 09.01.2021

Content of this journal is licensed under a Creative Commons Attribution 4.0 International License.

Available online at www.turkarchotolaryngol.net

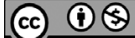

DOI: $10.4274 /$ tao.2021.6160

Objective: The aim of this study was to investigate how allergy practices in the otorhinolaryngology (ORL) residency departments in Turkey have changed over the last 20 years and to examine the current status in ORL residency training.

Methods: A 17-item questionnaire was developed following the study goals by a team experienced in allergy practices. The questionnaire was sent via e-mail to the program directors of all the 95 ORL residency departments in Turkey.

Results: A total of 60 (63.2\%) program directors completed the questionnaire. We found that allergy testing and immunotherapy had been performed in $70 \%$ and $28.3 \%$, respectively, at any time to date. The most common reason for discontinuing in allergy practices over time was "the changes introduced by the Turkish Social Security Institute as stated in the healthcare implementation communiqué" and "the difficulties in obtaining vaccine supplies from companies". Of all departments, allergy testing, immunotherapy, nasal smear, and nasal provocation tests were performed only by $35 \%, 8.3 \%, 28.3 \%$, and $1.7 \%$, respectively.

Conclusion: Allergy practices have been increasingly used, especially in the 2000s, but came to a standstill upon the changes introduced by the Turkish Social Security Institute as stated in the healthcare implementation communiqué. These findings suggest that allergy training, in the recent years, has remained in the background in ORL residency programs in Turkey. To achieve standardization in allergy training in ORL residency programs, professional associations and authorities should develop solutions in cooperation with legislators.

Keywords: Residency training, allergy, immunotherapy, skin prick test, otolaryngic allergy

\section{Introduction}

Allergic rhinitis (AR) is the most common cause of chronic rhinitis in children and adults. It is estimated to affect approximately $20 \%-40 \%$ of the global population (1). Considering such comorbidities as nasal polyps, rhinosinusitis, otitis media, and Meniere's diseases, AR plays a central role in the clinical practices of otorhinolaryngology (ORL). It is estimated that approximately $50 \%$ of all patients presenting to ORL outpatient departments have allergic components (2). Therefore, otorhinolaryngologists should be provid- 
ed with the knowledge of the diagnosis, treatment, and preventive medicine related to this patient group to a competent level during their residency training.

AR and otolaryngologic allergic diseases are a component of global ORL practices since the beginning of ORL residency training (3). In the United States, otolaryngic allergy education, including didactics and hands-on training, during ORL residency, has been mandated by the American Board of Otolaryngology and the Postgraduate Medical Education Accreditation Council (4). Also, the logbook, prepared by The European Union of Medical Specialist (UEMS) ORL Section, to provide standardization in ORL training programs in pan-Europe, aims to ensure ORL residents with the skills of allergy practice (5). Turkey is also a member of the Confederation of European Otorhinolaryngology-Head and Neck Surgery (ORL-HNS). However, there is currently a lack of sufficient data on AR diagnosis, treatment, and follow-up procedures in ORL residency departments, or the content of residency training in this regard in Turkey.

In Turkey, allergy practices have been performed since the 1970s, and interest in the approach has increased since the beginning of the 2000s (6). However, the reimbursement commission of the Turkish Social Security Institute (SSI), which is the most commonly used health insurance institution in Turkey, introduced changes to their scope with a healthcare implementation communiqué in 2013, by which allergy testing and immunotherapies performed by otorhinolaryngologists were excluded from the coverage (7). Allergy skin tests were included in the coverage again in 2016, but immunotherapies remained uncovered (8). It is unknown how these regulation changes have affected allergy practices in ORL residency programs or the education of the residents in Turkey.

In the present study, we investigate the changes in allergy testing and immunotherapy practices in the ORL residency training programs in Turkey over the last 20 years and examine the role of the current allergy practices in residency training.

\section{Methods}

A questionnaire was developed following the study goals by a team experienced in allergy-related practices (Figure 1). The questionnaire included 17 multiple-choice items, and comprised four parts, including demographic characteristics, allergy practices until today, current allergy practices, and resident training. In the questionnaire, some items could be responded to with more than one answer, while some items provided the opportunity to write comments.

The questionnaire was sent via e-mail to the department chairpersons and program directors of all the 95 departments currently providing ORL residency training in Turkey. The e-mail included a consent form explaining the purpose and the context of the survey. The research and a call for participation were announced through the networks used most commonly by Turkish otorhinolaryngologists (www. kanalkbb.com and www.kbb.org.tr). Reminder e-mails were sent every two weeks to the program directors that failed to respond. Data collection was completed in two months. The program directors who agreed to participate in the research completed the questionnaire online. Ethics committee approval for the study was obtained from the Clinical Research Ethics Committee of Pamukkale University (no: 60116787-020/54426).

\section{Results}

\section{Demographic Characteristics of ORL Residency Programs}

A total of $60(63.2 \%)$ program directors completed the questionnaire. The detailed demographic characteristics of the departments that participated in the study are presented in Table 1. Among the departments, $56.7 \%$ were public university hospitals, $35 \%$ were training and research hospitals, and $8.3 \%$ were foundation university hospitals. More than $70 \%$ of the departments had been providing ORL residency training for more than 20 years.

\section{Previous Allergy Practices in ORL Residency Programs}

Among the departments that participated in the study, allergy skin testing had been performed in any period in 42 (70\%) of the departments, with the distribution of testing by the period provided in Figure 2. Allergy testing was performed in 31 (51.7\%) departments until 2013, the year of the SSI payment cessation, while the number decreased to $10(16.7 \%)$ after 2013. The most common reasons stated for discontinuing allergy skin testing practices were "the changes introduced by the Turkish SSI in their healthcare implementation communiqué" (43.3\%) and "disallowance by hospital management” (21.7\%) (Figure 3). Only nine (15\%) departments had continued with allergy skin testing without interruption to the present day. The allergy skin testing methods most commonly performed by the departments were the lancet (43.3\%) and the multitest (35\%) epidermal prick test methods. According to the survey results allergy skin testing was never performed in 18 departments (30\%).

Among the departments, immunotherapy practices had been performed in 17 (28.3\%) in any period. There were $14(23.3 \%)$ departments that had performed subcutaneous immunotherapy and 11 (18.3\%) departments that had performed sublingual immunotherapy. The distribution of the departments by periods in which immunotherapy was provided is presented in Figure 2. The most common reason for discontinuing immunotherapy was importer-related problems in vaccine supply (Figure 3). 


\section{Allergy Practices in ORL Residency Programs}

1. Which of the following best describes the institution to which your clinic is affiliated?

$$
\begin{aligned}
& \text { o Public university hospital } \\
& 0 \text { Training and research hospital } \\
& \text { o Foundation university hospital }
\end{aligned}
$$

2. For how many years has your clinic been providing ORL residency training?

$01-5$ years

$05-10$ years

$010-20$ years

020 or more years

3. Has any allergy skin test been performed at your clinic at any time over the last 20 years?

0 Yes

0 No

4. If yes, in which of the following periods was skin testing for allergies performed? (You can mark more than one answer).

0 Not performed

o Before 2000

0 2000-2005

0 2005-2013

o 2013-2016

o After 2016

5. If allergy test practices were interrupted in your clinic, what was the reason? (You can choose more than one answer).

0 Interruption in test material supply due to importing company

o Lack of support by the hospital management

o The departure of the responsible employee from the clinic

o Non-payment for allergy testing by the reimbursement commission of the Turkish social security institute 0 Other .......
6. Which in vivo allergy test methods have been performed at your clinic to date? (You can mark more than one answer).

0 Epidermal test (Lancet)

0 Epidermal test (Multitest)

0 Intradermal test

0 Scratch test

0 Patch test

0 None performed

7. Have any immunotherapy practices been performed in your clinic at any time over the last 20 years?

0 Yes

0 No

8. If yes, in which of the following periods was the immunotherapy practice performed? (You can mark more than one answer).

0 Not performed

0 Before 2000

o 2000-2005

02006-2013

o 2013-2016

o After 2015

9. If immunotherapy practices were interrupted in your clinic, what was the reason? (You can mark more than one answer.)

0 Interruption in vaccination material supply due to importing company

0 Lack of support by the hospital management

0 The departure of the responsible employee from the clinic

o Non-payment for immunotherapy practices by the reimbursement commission of the Turkish social security institute

0 Other

10. Which immunotherapy practices have been performed at your clinic to date?

0 Subcutaneous

o Sublingual

0 Tablet

0 None performed
11. Is your clinic currently engaged in any allergy practices involving allergy testing or immunotherapy?

0 Yes

0 No

12. Is your clinic carrying out "nasal smear" assessments?

0 Yes

0 No

13. Is your clinic carrying out "nasal provocation tests"?

0 Yes

o No

14.Are your allergy practices carried out by a full-time academician?

0 Yes

0 No

15. Do you have allergy nurses?

0 Yes

0 No

16. Do residents in your clinic's ORL residency program actively participate in allergy practices?

0 Yes

o No

17. Which of the following practices do the residents in your clinic perform? Please mark which practices residents can perform.

0 Carry out and interpret allergy skin tests on patients o Interpret specific IgE allergy test (RAST) o Calculate immunotherapy doses using formulas 0 Administer immunotherapy injections

Figure 1. Allergy Practices in ORL Residency Programs

ORL: Otorhinolaryngology

Table 1. Demographic characteristics of residency programs

\begin{tabular}{l|l|l|l|l}
\hline $\begin{array}{l}\text { ORL residency training } \\
\text { period }\end{array}$ & $\begin{array}{l}\text { Public university } \\
\text { hospital (n) }\end{array}$ & $\begin{array}{l}\text { Training and research } \\
\text { hospital (n) }\end{array}$ & $\begin{array}{l}\text { Foundation university } \\
\text { hospital (n) }\end{array}$ & $\begin{array}{l}\text { Total } \\
(\mathbf{n}, \%)\end{array}$ \\
\hline $1-5$ years & 1 & 1 & 1 & $3(5 \%)$ \\
\hline $5-10$ years & 1 & 1 & 2 & $4(6.7 \%)$ \\
\hline $10-20$ years & 4 & 3 & 2 & $9(15 \%)$ \\
\hline$>20$ years & 28 & 16 & $5(8.3 \%)$ & $44(73.3 \%)$ \\
\hline Total $(\mathrm{n}, \%)$ & $34(56.7 \%)$ & $21(35 \%)$ & $60(100 \%)$ \\
\hline
\end{tabular}


Only one (1.7\%) department never discontinued their immunotherapy practices. According to the survey results, immunotherapy was never performed in 43 (71.7\%) departments.

\section{Current Allergy Practices of ORL Residency Programs}

Among the departments, 21 (35\%) were performing allergy skin testing at the time of the survey, while five $(8.3 \%)$ of these were also performing immunotherapy. There were 17 (28.3\%) departments carrying out nasal smear assessments, while nasal provocation tests were performed in only one (1.7\%). It was stated that allergy practices were carried out by a full-time academician in 18 (30\%) departments, while eight (13.3\%) departments retained an allergy nurse. The distribution of allergy practices at the time of the survey is presented in Figure 4.

\section{Allergy Practices Being Actively Performed by Residents}

Among the departments participating in the study, 20 (33.3\%) reported that they were actively performing allergy practices during residency training, while 40 (66.7\%) departments reported that their residents were not receiving allergy practice training. It was also reported that residents were performing and interpreting allergy skin testing in 20 (33.3\%) departments, interpreting specific Immunoglobulin E allergy tests in ten (16.7\%) departments, performing immunotherapy injections in three (5\%) departments, and were able to calculate immunotherapy doses using formulas in one (1.7\%) department. The detailed allergy practices actively performed by residents are presented in Table 2 .

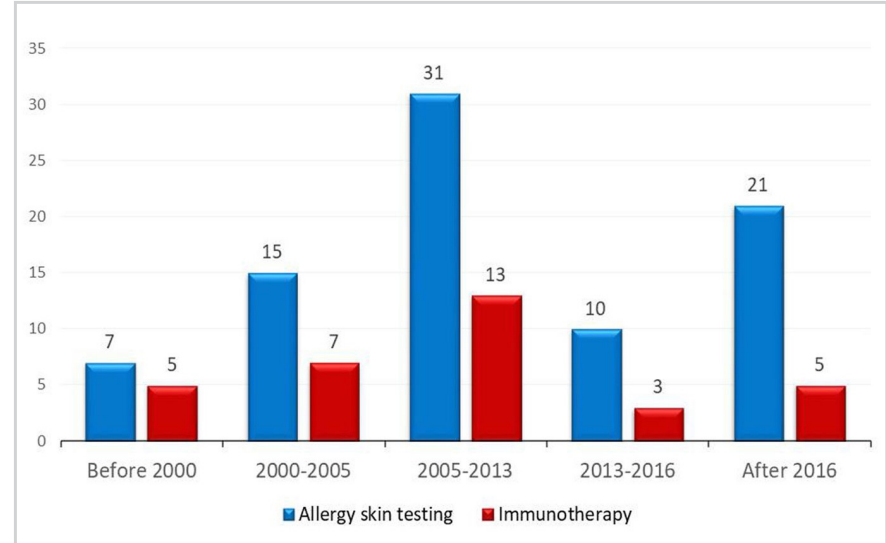

Figure 2. The number of residency programs performing allergy skin testing and immunotherapy according to time periods

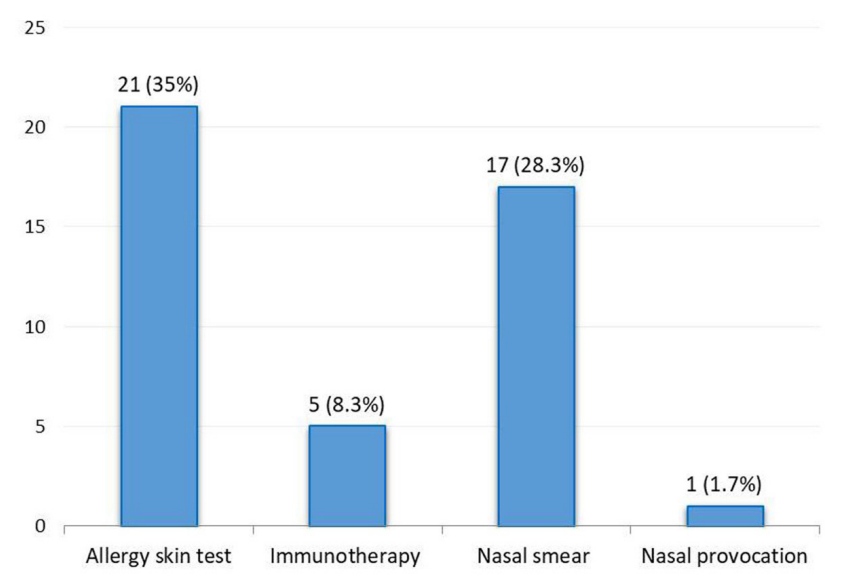

Figure 4 . The allergy practices currently performed by the residency programs.

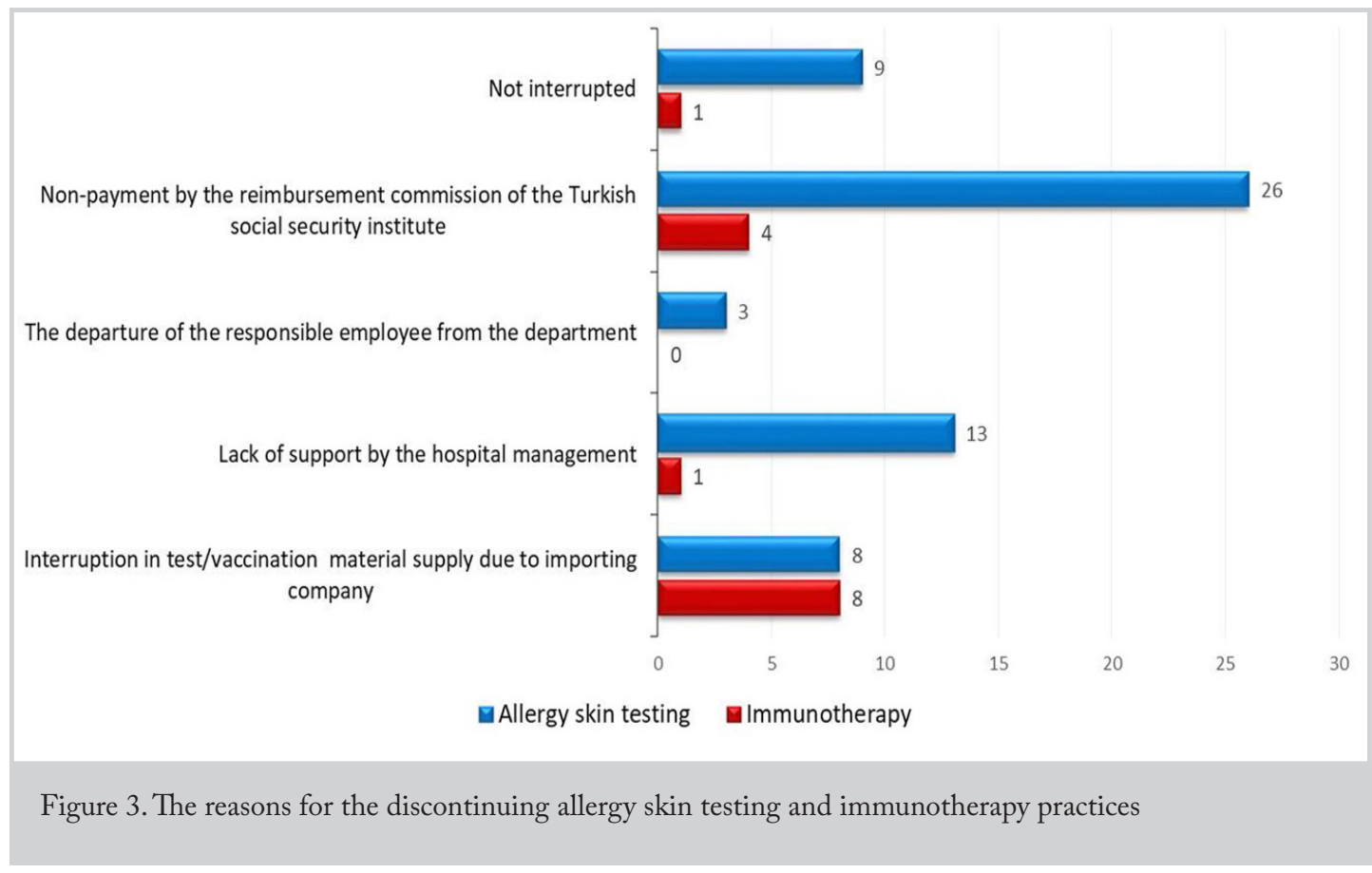




\begin{tabular}{l|l|l|l|l}
\hline Table 2. The allergy practices actively performed by residents & & & \\
\hline & $\begin{array}{l}\text { Public university } \\
\text { hospital (n) }\end{array}$ & $\begin{array}{l}\text { Training and research } \\
\text { hospital (n) }\end{array}$ & $\begin{array}{l}\text { Foundation university } \\
\text { hospital (n) }\end{array}$ & $\begin{array}{l}\text { Total } \\
\text { (n, \%) }\end{array}$ \\
\hline Carry out and interpret allergy skin tests & 11 & 7 & 2 & $20(33.3 \%)$ \\
\hline Interpret specific IgE allergy test & 6 & 4 & - & $10(16.7 \%)$ \\
\hline Administer immunotherapy injections & 2 & 1 & - & $3(5 \%)$ \\
\hline Calculate immunotherapy doses & - & 1 & - & $1(1.7 \%)$ \\
\hline IgE: Immunoglobulin E, n: Number & & & & \\
\hline
\end{tabular}

\section{Discussion}

$\mathrm{AR}$ is a common condition all around the world, particularly in developed countries. It has a negative effect on life quality and is increasing in prevalence. Its prevalence is reported to be $20 \%-25 \%$ in Turkey (9). Given the high prevalence of $\mathrm{AR}$ and the frequency of comorbidities and complications, allergy practices have an important place in ORL procedures. In Turkey, the first national core program activities were initiated under the Turkish ORL-HNS Society in 2006, and a "Residency Core Training Program (RCTP)" containing all necessary knowledge and skills was prepared within the scope of this program that could be used as a guide by institutions providing residency training (10). The program recommended establishing an "allergy outpatient clinic" at every center providing ORL residency training. Moreover, it aimed to ensure that ORL residents gained the necessary skills to carry out allergy skin tests, nasal provocation tests, and nasal cytology and serological allergy tests. The RCPT was updated in the subsequent years, with "allergen-specific immunotherapy" added to the previous learning objectives. However, whether or not allergy education and training will be included in ORL residency programs in Turkey is uncertain. To our knowledge, this is the first study to evaluate allergy practices and education in departments that provide ORL residency training in Turkey.

Allergy skin testing and immunotherapy are the most important allergy practices in the diagnosis and treatment of allergic diseases (11). In the presented study, we found that the number of departments carrying out allergy skin tests in Turkey started to increase after 2000, rose to 31 after the RCTP was launched, but rapidly decreased to 10 after the change in Turkish SSI regulations in 2013. Likewise, the number of departments performing immunotherapy practices decreased from 13 to three following the change in SSI regulations. After otorhinolaryngologists were once more entitled to carry out allergy skin testing in 2016, an increase was seen in the number of departments performing allergy practices, albeit the numbers seen in the past have not yet been reached. These results show us that the official health policies in countries are very effective in resident training. The program directors of the departments also expressed the SSI regulation changes as the most important reason for discontinuing allergy skin testing practices. Besides, difficulties in obtaining vaccines due to importerrelated problems were given as one of the leading reasons for discontinuing immunotherapy practices.

The literature contains few studies evaluating allergy practices in ORL residency programs. The study by Osguthorpe (12) in 1985 reported that only 8\% of the ORL residency programs in the United States met the minimum criteria recommended by the American Academy of Otolaryngic Allergy. In the following years, the 2006 study by Lin and Mabry (3) reported a rate of residency programs that addressed active allergy practices in the United States of approximately $62 \%$. Finally, the study by Bailey et al. (13) in 2014 found that this rate had increased to 73\%. These studies suggest that allergy practices have witnessed a gradual increase in ORL residency programs in the United States. In the presented study, the proportion of departments with allergy programs, which peaked at $51 \%$ in the early 2010 s, is only $35 \%$ today. Among the departments participating in the survey, the proportion of those that were performing allergy skin testing and immunotherapy practices at the time of the survey were $35 \%$ and $8.3 \%$, respectively. The proportion of the departments carrying out nasal smear and nasal provocation testing practices, which, again, are very important in the differential diagnosis of AR among allergy practices, were approximately $28 \%$ and $1.5 \%$, respectively, at the time of the survey. These findings suggest that allergy practices, in the recent years, have remained in the background in ORL residency programs in Turkey.

Allergy education in an ORL residency program should include hands-on training in addition to theoretical training. In the presented study, however, we found that residents were actively participating in allergy practices only in $33 \%$ of the residency programs in Turkey. Even though the theoretical and practical training issue in AR is broadly included in both the UEMS-ORL section logbook and the RCTP, it is understood that currently there are deficiencies in this regard in both university and training and research hospitals in Turkey. Given that allergy education is an inseparable part of the ORL residency program, arrangements should be made to increase the number of operational allergy laboratories in ORL residency departments. 


\section{Conclusion}

In this study, we observed that allergy education in ORL training programs in Turkey has varied in both quantity and quality, over time and across institutions. Allergy practices were increasingly used, especially in the 2000s, but came to a standstill upon the changes introduced by the Turkish SSI in their healthcare implementation communiqué. We further concluded that import-related problems in accessing testing and vaccination materials in the recent years were an important factor in the lack of progress in allergy practices. These results show us that the official health policies in countries are very effective in resident training. To achieve standardization in allergy training in ORL residency programs, professional associations and authorities should develop short- and long-term solutions in cooperation with legislators. The priority, however, is to increase the number of operational allergy laboratories in the departments that provide ORL residency training.

\section{Acknowledgments}

We would like to thank the department chairpersons and program directors of the ORL residency departments who responded to the questionnaire, for their valuable contribution to this project.

Ethics Committee Approval: Ethics Committee approval for the study was obtained from the Clinical Research Ethics Committee of Pamukkale University (no: 60116787020/54426) on $08 / 08 / 2019$.

Informed Consent: This is survey research and the survey was sent via e-mail to the department chairmen and program directors of all the 95 departments currently providing ORL residency training in Turkey. The e-mail included a consent form explaining the purpose and the context of the survey.

Peer-review: Externally peer-reviewed.

\section{Authorship Contributions}

Conception: E.M., C.O.K., B.T., Design: E.M., C.O.K., B.T., Supervision: E.M., C.O.K., B.T., Materials: E.M., C.O.K., B.T., Data Collection and/or Processing: E.M., C.O.K., Analysis and/or Interpretation: E.M., C.O.K., B.T., Literature Review: E.M., C.O.K., B.T., Writing: E.M., C.O.K., B.T., Critical Review: C.O.K., B.T.

Conflict of Interest: No conflict of interest was declared by the authors.

Financial Disclosure: The authors declared that this study has received no financial support.

\section{References}

1. Bousquet J, Khaltaev N, Cruz AA, Denburg J, Fokkens WJ, Togias A, et al. Allergic rhinitis and its impact on asthma (ARIA) 2008 update (in collaboration with the World Health Organization, GA(2)LEN and AllerGen). Allergy 2008; 63: 8-160. [Crossref]

2. Lane AP, Pine HS, Pillsbury HC 3rd. Allergy testing and immunotherapy in an academic otolaryngology practice: a 20-year review. Otolaryngol Head Neck Surg 2001; 124: 9-15. [Crossref]

3. Lin SY,Mabry RL. Allergy practice in the academic otolaryngology setting: results of a comprehensive survey. Otolaryngol Head Neck Surg 2006; 134: 25-7. [Crossref]

4. Franzese $\mathrm{CB}$. The current status of allergy training in otolaryngology residency programs. Curr Opin Otolaryngol Head Neck Surg. 2012; 20: 205-8. [Crossref]

5. Surda P, Barać A, Deghani P, Jacques T, Langdon C, Pimentel J, et al. Training in ENT; a comprehensive review of existing evidence. Rhinology Online 2018; 1: 77-84. [Crossref]

6. Topuz B, Kara CO, Çanakçıŏlu S, Günhan K, Coşkun BU, Keleş $\mathrm{E}$, et al. How are we in the field of 0torhinolaryngologic allergic diseases? KBB Forum 2020; 19: 161-8. [Crossref]

7. Updates to the Social Security Institute Healthcare Implementation Communiqué. Turkey - Legal Gazette 2013 March (cited 2020 September 10). Available from: https://www.resmigazete.gov.tr/ eskiler/2013/03/20130324-3.pdf [Crossref]

8. Updates to the Social Security Institute Healthcare Implementation Communiqué, Turkey - Legal Gazette October 2016 (cited 2020 September 10). Available from: https://www.resmigazete.gov.tr/ eskiler/2016/10/20161007-12.html [Crossref]

9. Cingi C, Topuz B, Songu M, Kara CO, Ural A, Yaz A, et al. Prevalence of allergic rhinitis among the adult population in Turkey. Acta Otolaryngol 2010; 130: 600-6. [Crossref]

10. Turkish ORL-HNS Residency Core Training Program. Turkish ORL-HNS Competency Board 2012 (cited 2020 September 10). Available from: https://www.kbbyeterlik.org.tr/ TKBBBBCYKData/Uploads/files/ucep.pdf [Crossref]

11. Seidman MD, Gurgel RK, Lin SY, Schwartz SR, Baroody FM, Bonner JR, et al. Guideline Otolaryngology Development Group. AAO-HNSF. Clinical practice guideline: allergic rhinitis. Otolaryngol Head Neck Surg 2015; 152: S1-43. [Crossref]

12. Osguthorpe JD. Allergy and immunology training in otolaryngology residency programs. Arch Otolaryngol 1985; 111: 779-80. [Crossref]

13. Bailey SE, Franzese C, Lin SY. Allergy education in otolaryngology residency: a survey of program directors and residents. Int Forum Allergy Rhinol 2014; 4: 104-9. [Crossref] 